\title{
Improving Bilingual Education Quality in Ethnic Minority Areas of Yunnan: Viewing from Ecolinguistics Stance
}

\author{
ZHONG Wei \\ School of Foreign Languages and Literature \\ Yunnan Normal University \\ Kunming, China
}

\author{
DUAN Congyu * \\ Higher Education Research Institute \\ Yunnan Normal University \\ Kunming, China \\ *Corresponding author
}

\begin{abstract}
The methods and quality of bilingual education has fundamental effects on ecolinguistics environment of ethnic minority areas. Efficient bilingual education can not only improve the language ecology system, but also advance the learning efficiency of ethnic minority students in all disciplines. From Halliday's ecolinguis tic research paradigm, this paper points out bilingual education in ethnic minority areas should suit the measures to differing conditions in terms of locality and time. On the basis of discussion on the current bilingual education status and problems, the paper indicates that four aspects of bilingual education, namely curriculum designing, textbooks developing, te acher training and educational resources developing, should obey the ecological rules.
\end{abstract}

Keywords-ecolinguistics; ethnic minority areas; bilingual education; quality improvement

\section{INTRODUCTION}

Bilingual education in Yunnan ethnic minority areas has a long history. At the beginning of the founding of New China, a bilingual education policy was formulated[1]. In the 1980s, bilingual education in Yunnan entered the first round of rapid advancement, and carried out a large number of bilingual experimental projects with purpose, planning, steps and certain norms, such as minority nationality professional training courses, Chinese and minority language(s) bilingual training projects[2]. In order to implement the "Decision of the State Council on Accelerating the Development of Ethnic Education" and the spirit of the Sixth National Conference on Ethnic Education, the "Regulation on the Promotion of Ethnic Minority Education in Yunnan Province" was officially promulgated and implemented in 2013. The Regulation marks a new development of bilingual education in Yunnan Province; consequently, bilingual education in pre-school and elementary school has become the focus of the future.

The status quo of bilingual education in ethnic areas of Yunnan Province is closely linked to the historical development of national integration. Under the influence of many factors such as complex geographical environment, large-scale ethnic migration and multi-ethnic cross-integration, Yunnan ethnic minorities have formed the characteristics of diverse and mixed ethnic groups [3]. Most of the ethnic minorities in the province are small-scale settlements in villages and townships. They are mixed with the Han people in counties and cities, and they constitute the distribution characteristics of large mixed cohabitation and small settlements with own groups as the main body[4]. Similar to the language community of "Chinese Monolingual Area", "Mandarin Monolingual Area", "Min and Han Bilingual or Multilingual Area” in Xinjiang[5], the language use in Yunnan Province is as follows. Firstly, merely using the national language; secondly, using both the national language and Chinese; thirdly, using the national language, Chinese and other national languages (trilingual and multi-lingual areas); and fourthly, national languages disappear, using only Chinese. Meanwhile, there are 16 cross-border ethnic groups among the 25 ethnic minorities in Yunnan, that is, ethnic groups living in China and neighboring countries. In addition to Hui nationality, the other 23 ethnic groups use 27 languages. The languages of the 25 ethnic minorities belong to the SinoTibetan and South Asian languages, and there are 52 new and old languages.

These specific and special circumstances have long restricted the improvement of the quality of bilingual teaching in minority areas of Yunnan Province. For a long time, referring to the improvement of bilingual teaching quality, bilingual textbooks [6], bilingual teachers[7], and bilingual education policy issues[8] have al ways been the main research issues of the academic circle. With the continuous research and deep understanding of culture and language ecology, ecolinguistics has gradually become a new perspective to improve the quality of bilingual teaching.

\section{BASIC RESEARCH PARADIGM OF ECOLINGUISTICS}

In recent years, with the development of applied linguistics, research branches that are compatible with the development of social culture, geography and ecological environment have been gradually formed, such as national linguistics, human linguistics, and sociolinguistics etc. These branches reflect the ideas of the ecological language view, such as the study of endangered languages by national linguistics, the study of language production, evolution and extinction by human linguistics, and the study of linguistic diversity of sociolinguistics. ecolinguistics or linguistic ecology is derived from the holistic worldview, which is a combination of 
ecology and linguistics. In recognition of the three basic principles of ecology, linguistics and ecology have five interfaces: language diversity, the existence of endangered languages, the relationship between biodiversity and linguistic/cultural diversity, ecological and non-ecological factors of the language system, and ecological critical discourse analysis[9].

Haugen first proposed and used the concept of "language ecology"[10]. By metaphorically synthesizing the speech environment and the biological environment, he defines the concept of "language ecology" as the study of the interaction between any particular language and the environment. This metaphor lays one of the mainstream research paradigms of ecolinguistics, namely the use of ecological concepts such as "environment", "interaction" and "language world system" to study psycholinguistics and sociolinguistic phenomena. The core is to study all the environmental elements that may enhance or weaken the language function. It is believed that the imbalance of language ecology will lead to cultural ecological imbalance and ultimately destroy the sustainable development of human society. Therefore, the study of language programming mostly adopts the Haugen paradigm to explore the ecological balance of human development from the existence of language and culture.

The second research paradigm of ecolinguistics is proposed by Halliday, which understands the concept of "ecology" in a biological sense, and investigates the role of language in the improvement and aggravation of environmental problems. This paradigm directly links the change of language with the development of natural ecology. It is believed that the education and planning of language must be based on the preservation of the good living environment of human society. Halliday's paradigm recognizes the phenomenon of "survival of the fittest" in biological evolution, recognizing that the existence and disappearance of language is influenced by the humanities and the social environment. It is not advisable to overemphasize large-scale learning of languages (such as Latin) that are on the verge of extinction or that do not contribute to the survival and development of human society. This paradigm will recognize the positive and negative effects of language in promoting and hindering environmental change.

\section{The Path of Bilingual education Quality IMPROVEMENT BASED ON ECOLINGUISTICS}

Starting from Halliday's research paradigm, the author believes that bilingual teaching in ethnic areas should be based on the current situation of the language and culture environment in the region, and follow the basic principle of "adapting to local conditions and changing from time to time", that is, the planning and implementation of any method or approach should be based on the local basic situation. From the perspective of language selection, it is not advisable to emphasize "Chinese center" or "minority language alone". The ecological improvement of bilingual education quality should be completely reflected in the four aspects, namely, bilingual curriculum, bilingual textbook development, bilingual teacher training, and bilingual teaching resources.

\section{A. Balancing the development of Chinese and Minority Languages in Bilingual Curriculum}

Domestic scholars have pointed out that bilingual education in ethnic areas presents the phenomenon of "lack of attention and teaching in a formative way" [11]. In the mean time, public schools have started a unified national curriculum from the beginning of primary school. The use of Mandarin textbooks in all provinces and regions, as well as testing language and teaching language with Mandarin only, which have become the main reasons hindering the long-term development of bilingual education [12]. Therefore, a large number of bilingual programs are currently active in the preschool stage [13]. In the primary school stage, except for some ethnic primary schools, bilingual courses are not offered. Some ethnic primary schools cannot implement bilingual teaching because of various "unified" norms and teachers. "Bilingual education" exists only in the curriculum in some schools, and there is no actual teaching content.

The core cause leading to this phenomenon is the language concept that overemphasizes the instrumentality of language. That is, only minority languages are the tools for learning Chinese course. Once students begin to learn Chinese or master Chinese, they no longer need to learn ethnic minority languages. Some scholars believe that from the perspective of language instrumental characteristics, if a disadvantaged nation does not actively learn inter-ethnic or regional lingua franca, its development will be hindered. Shen believes that the rationality of language instrumental appeal lies in the needs of the employment market and national identity, but also points out that language is not only instrumental, but also has the value as the cultural heritage.

Ecolinguistics believes that the survival of language changes with the development of the times, and language education should also follow the principle of "survival of the fittest". Minority culture is part of Chinese culture, and minority languages are both a manifestation of their culture and a window to learn their culture. The setting of bilingual courses needs to balance the objective needs of the development of Chinese and minority languages.

First of all, adopt the principle of "mother tongue priority", such as the "Bai and Han Bilingual Education Project" in Shilong Village, Jianchuan, Dali [14]. Cummins shows that native speakers are more likely to learn new languages and mother-tongue teaching can effectively promote students' literacy. Learning a new language in one's own language can better promote students' mastery of the new language. At the same time, Hornberger pointed out that when multilingual learners dominate the power in the "Bilingual Community", that is, when bilingual teaching leans toward the traditionally disadvantaged side, the language vulnerable groups can learn more, faster and better. Most ethnic areas in Yunnan are multilingual areas. Even in ethnic autonomous areas, Chinese culture is still the representative of advanced culture. Minority culture is comparably disadvantaged, while minority students are weak to some extent. In this case, using the mother tongue of the ethnic students as teaching medium can help students master the knowledge of other subjects (mathematics, etc.). However, it must point out that if the language of the main 
ethnic group in an ethnic minority region has died, or most ethnic groups have adopted Chinese as their first language, their native language is already Chinese, not the minority language in the traditional sense. There are also some ethnic students, residing in more developed counties, whose mother tongue is not a minority language. For these groups, if there is no minority language environment among family members, the bilingual course of "Minority language" will increase their learning stresses. The third situation is that a large number of ethnic groups live in multi-lingual areas, and the same school will have one dominant group with a small number of other ethnic students. For such schools, students of minority groups can be provided with after-school tutoring to achieve "learning in their mother tongue”.

Secondly, implementing the curriculum development principle of "timely and complete integration". As mentioned above, after entering primary school, there is a unified national curriculum in the basic education stage. In the kindergarten class and the first to third grades of primary school, and even in the sixth grade, the bilingual pathway course can effectively help minority students to achieve the transition of learning. Timely and sufficient integration cannot only help ethnic students to master Chinese quickly, but also help them to learn other subjects better, and enhance their cultural identity and national pride in the process of consolidating and learning their own language. At present, facing the objective requirements of "de-primeization" in the pre-school stage, and the primary school stage squeezed by the disguise of the junior high school entrance examination and the middle school entrance examination, developing the pathway course linking kindergarten and primary school are the important issue. Students have an urgent need to solve problems in the cultivation of learning habits and the formation of learning consciousness, while the language differences of students in ethnic areas have deepened the difficulties they face. Thus, in addition to the bilingual language teaching for students, it is necessary to carry out the teaching the bilingual subjects knowledge through Chinese and minority languages.

\section{B. Developing Bilingual Teaching Materials with Rich National Cultural Life}

Teaching materials are an important guarantee for the development of teaching. The content of the textbook reflects the teaching content, which is the dominant embodiment of the syllabus. However, a large number of studies have shown that the lack of high-quality bilingual teaching materials and teaching resources is an important reason hindering the development of bilingual teaching. The current bilingual textbooks present the following problems: 1 lack of guidance on curriculum standards, 2 single-form textbook, 3 modeled textbooks, 4 lack of authentic national life, etc.[15] In general, many problems in bilingual textbooks stem from the lack of systematic design of bilingual courses and the lack of systematic bilingual talent training.

With the development of second language acquisition research, for minority students in Yunnan, though instrumental motivation has a stronger role for second language or foreign language learners, integrative motivation is the root of longterm language learning for learners;[16] at the same time, integrative motivation is also the most relevant factor for learning outcomes[17]. Integrative motivation refers to the strong interest of students in learning the language about the language itself, the person who speaks the language, or the culture that the language carries, and then presents a status which hope to be integrated into the target language culture. For ethnic students, the use of their own language to portray their cultural life is a manifestation of integrative motivation.

Ecolinguistics emphasizes that language education must be based on maintaining a good living environment in human society. If there is a lack of national cultural life in bilingual textbooks, students only learn to use their own language to describe the life of other people. This only allows students to consolidate the instrumental motives of their language learning, and weaken the integrative motivation that should be enhanced. Secondly, from the perspective of language understanding, learning language with things that are common in life can stimulate students' interest in learning, especially children. Hence, bilingual textbooks without national cultural life are bound to have a negative impact on the preservation of the nation's living environment.

\section{Bilingual Teacher Training Based on Local Human Capital}

High-quality teachers are the key to improving the quality of national education. Chapter 9 of the Outline of the Medium and Long-Term Education Reform and Development Plan for Yunnan Province (2010-2020) clearly states that:

"Actively cultivate the talents of the 'Min and Han' and increase the training of bilingual teachers who are familiar with minority languages and Chinese language. Increase investment in establishing provincial and state (city) bilingual teacher training bases."

However, bilingual teachers have not been able to meet the requirements of bilingual education either quantity or quality. Bilingual teachers have low enthusiasm for teaching tasks, weak target content for bilingual training designed for them, and subjective and objective factors such as not graduated from bilingual education majors which would provide systematic academic training, resulting in low quality of bilingual teachers.

Yunnan Province has taken different forms of experimentation for cultivating bilingual teachers. From 2001 to 2008, the Provincial Department of Education organized training for more than 5,000 bilingual teachers. Bilingual teaching conference has been held every year, and experts and scholars are invited to give lectures. Through bilingual meetings, training, briefings, research and other forms, bilingual teaching experience has been exchanged through multiple channels. Some institutions also set up bilingual majors or special programs to train bilingual teachers from ethnic areas. However, there are still some teachers in ethnic areas who cannot understand the minority language and some who understand ethnic languages are reluctant to return to ethnic areas[18]. Therefore, it may be a more effective way to train bilingual teachers from local human capital. On the one hand, it is easier to train the teaching skills from local people who understand the minority language than to teach a new 
language to teachers who know the pedagogy. On the other hand, because people are chosen from the local area, it can reduce the migration of human capital. The Bai and Chinese Bilingual Education Project, Shilong Village in Jianchuan County, Dali, recruits local literacy and junior high school diplomas to train pedagogy, which effectively made up for the shortage of teachers' quality [19] At the same time, teachers are highly motivated to work because they were provided a stable and well-paid job. However, the biggest difficulty in the Dali area is that due to the lack of teachers' academic qualifications, it is impossible for them to become full-time faculties who could receive more benefits. Only through special grants or upgrading their academic qualifications can the teacher problem be solved in the long run. Thus, in order to train bilingual teachers based on local human capital, we can try the following programs as screening methods to achieve the Chinese old saying that "what is taken from the people is used in the interests of the people".

\section{1) Junior high school oriented bilingual teacher training} program

From the junior high school, select some students who are familiar with their own language and have a solid knowledge system of other disciplines as the key training objects, and use the holidays to carry out focused training of bilingual teaching methods. If they can be admitted to high school, they could be accepted as a part-time "bilingual teacher" regardless of whether they can be enter the university. In this way, on the one hand, it can improve the general state of poor bilingual education; on the other hand, it can promote the increase of junior high school enrollment.

2) From senior high school to college free "bilingual" teacher training program

Students who know well about their national language (tested by a designated language) can apply for a free "bilingual" teacher training program in the third year of high school and sign a relevant agreement with the local education bureau. As long as the student successfully passes the college entrance examination and obtains the admission notice from the normal colleges, he or she can study for the relevant teacher-training majors free of charge and return to the local area as a bilingual teacher after graduation. It is true that this requires the local education bureau to sign relevant orientation admission agreements and bilingual teacher training agreements with provincial teachers colleges.

3) In-service minority teacher national language training program

For in-service teachers who do not understand ethnic languages, they can achieve their conversion through minority language training programs. If teachers in minority areas are not ethnic minorities, the motivation for learning the minority language is very weak, but the teachers who are ethnic minorities have a stronger willingness to learn the minority language, and at the same time they can realize the help of the minority language in teaching[20]. Conducting a certain degree of ethnic language courses for working minority teachers, so as to enable them to use simple minority language to communicate with students and to teach, can more effectively improve the quality of teaching and the low quality of teachers.

\section{Integrating Information Technology in Bilingual Teaching Resources}

Under the impetus of modern distance education projects in rural primary and secondary schools, information technology has penetrated into the field of education in ethnic areas[21]. Projects such as multimedia courseware and ebooks are gradually covering primary and secondary schools in ethnic areas. Studies have shown that the multimedia word source literacy system in Tibetan can effectively improve the effect of Tibetan students' knowledge of Chinese characters and improve their interest in learning Chinese. However, the research by Zhao et al pointed out the following problems. Firstly, the minority nationalities are less involved in the bilingual education informatization research team; secondly, the research horizon of minority bilingual education informatization needs to be expanded continuously; thirdly, lack of evaluation and empirical research; and finally, theoretical and practical knowledge still need further integration [22]. These problems have become part of the reasons for the development of stagflation of bilingual information-based teaching resources.

The language problem is not only the difficulty faced by students, but also the obstacle faced by teachers. Only by prioritizing breakthroughs in language barriers, multidisciplinary bilingual education can truly achieve leapfrog development in ethnic areas. The Key Laboratory of Educational Informationization of Nationalities (MoE) of Yunnan Normal University has developed the Wa and Han Basic Bilingual Vocabulary Learning System (version 1.0). Through the system's voice recognition function, it can help students learn Chinese and help teachers learn Wa language. This is a new attempt by Yunnan Province to confront the construction of bilingual educational information resources in ethnic areas.

The rapid development of network information technology provides an opportunity for the realization of cross-regional education equity. Learning through using network information technology is the biggest educational ecology in the current education reform. The development of bilingual educational resources must adapt to this developmental demand, and take advantages of the development of deep learning and computational linguistics to achieve a new round of breakthrough of education quality improvement. The bilingual educational resources that integrate network information technology not only can promote the communication between experts and scholars and the frontier teachers, but also stimulate the interest of students in ethnic areas.

\section{CONCLUSION}

Curriculum setting, textbook development, teacher development and educational resources are the core factors that must be considered to optimize the structure of education and improve the quality of teaching. Viewing from the ecological linguistics perspective, improving the quality of bilingual education in ethnic areas must pay attention to the 
development of education, as well as maintain the environment for the survival and development of ethnic minorities. The bilingual curriculum in Yunnan ethnic areas maintains the ecology of language education by balancing the development of the language of the people; bilingual textbooks are developed through the enrichment of national cultural life to ensure the inheritance of national culture; bilingual teachers are trained to strengthen the cultural subject based on local human capital ecology; and bilingual educational resources through the integration of network information technology adapt to the ecology of the escalating educational approach. The specific work of these four aspects should be "mutually complemented" to achieve the steady development of bilingual education in Yunnan province.

\section{REFERENCES}

[1] Cummins, J. Interdependence of first and second-language proficiency in bilingual children. In E. Bialystock, (ed.). Language Processing in Bilingual Children. Cambridge: Cambridge UP, 1991.

[2] Dai. Q. X. The status quo and tasks of bilingual education research of ethnic minorities in south China. MINZCUZ GYAUYUZ YENZGIU. 1996(2): 54-58, 62.

[3] Fan, J. J. A review of ecological linguistics research. Foreign Language Teaching and Research. 2005(2):110-115.

[4] Haugen, E. The Ecology of Language. Standford: Stanford UP, 1972.

[5] Halliday, M. New ways of meaning: the challenge to applied linguistics. Journal of Applied Linguistics, 1990 (6).

[6] Hornberger, N. H. The continues of biliteracy and the bilingual educator: Educational linguistics in practice. International Journal of Bilingual Education and Bilingualism, 2004 (7).

[7] Hu, D. Y. Trilingual Education of Members from Ethnic Minority nationalities in Yunnan. Kunming: Yunnan UP, 2007.

[8] Hu, W. J., Fu, M. J., \& Pan, W. L. Primi speech recognition based on deep neural network. 2016 IEEE 8th International Conference on Intelligent Systems (ISAI2016). Paper Number ISAI2016-I213. July 7th, 2016.

[9] Li, F. J. A study on the bilingual education of minority people in Yunnan. Journal of Chuxiong Normal University. 2011 (11): 25-30.

[10] Shen. H. C. On state orientation in education policy and its problems: A case study of bilingual education in Mangshi County, Yunnan. Journal of Nanjing Tech University (Social Science Edition), 2014(4): 122-127, 134.

[11] Wang, Z. Z. \& Wang, J. A survey on the effects and problems of bilingual teaching in ethnic regions--with Lhasa as example. Contemporary Education and Culture. 2013(1): 102-110.

[12] Wang, G. \& Zhang, X. Internationalization and localization of bilingual education projects in southwestern multiethnic areas--A study on Bai and Chinese bilingual education project in Jianchuan County of Dali Bai Autonomous Prefecture of Yunnan Province. Journal of Research on Education for Ethnic Minorities, 2016(2): 89-93.

[13] Xu, T. \& Li, P. X. A new approach to bilingual education in minority areas--A Study on the teaching of Chinese characters in Tibetan bilingual multimedia sources. China Educational Technology. 2012(3):22-25.

[14] Yang, Y. \& Deng, H. The problems and countermeasures of the construction of bilingual teaching materials for ethnic minority primary schools in Yunnan--Taking Yi nationality as an example. Journal of Jiamusi Vocational Institute. 2016(11): 155-156.

[15] Yuan, Y. C. Attitude and Motivation for English Learning of Ethnic Minority Students in China. Shanghai: Shanghai Foreign Education Press, 2007.

[16] Zhang, M. Basic information of Xinjiang and language planning. Journal of South-Central University for Nationalities (Humanities and Social Sciences). 2012 (3): 22-25.

[17] Zhang, M. \& Wang, A. S. Diversified construction of preschool bilingual education for ethnic minorities in Xinjiang. Journal of Research on Education for Ethnic Minorities. 2008(1): 86-91.

[18] Zhao, H. C, Wang, Y., Wang, L., Yan, W. B. Current situation and prospect of research on minority bilingual education in ICT environ ment. Modern Educational Technology. 2015(10): 12-18.

[19] Zhong, W. Professional Development Needs of Secondary School English Teachers in Ethnic Minority Areas of China [Doctor Dissertation]. UK: Nottingham University, 2015.

[20] Zhong, W. \& Gan, J. H. New Technology on Wa Culture Protection and Inheritance Project Report. Kunming: Key Laboratory of Educational Informatization of Nationalities (MoE). 2017.

[21] Zhu, H. \& Cao, L. A literature review of the historical process of bilingual education in minority areas of Yunnan. Journal of Simao Teachers' College. 2012 (3): 69-72.

[22] Zhu, H. \& Yuan, C. L. The development of bilingual education policy for ethnic minorities in Yunnan. Southwestern Education Theory (Quarterly). 2011(2): 57. 